\title{
QUALIDADE DE ENSINO E CINISMO ÉTICO NO JORNALISMO
}

\author{
Marketing-jornalismo e jornalismo de compadre são práticas \\ correntes nas empresas de comunicação em que o cinismo ético, \\ os interesses econômicos e políticos superam o compromisso \\ com a sociedade civil e a democracia
}

Em artigo na revista Imprensa, edição de março de $1994^{1}$, o jornalista Alexandre Garcia, da Rede Globo de Televisão, afirmava que "nesses quase 20 anos de Brasília, adotei como forma de sobrevivência neste 'Butantã' a manutenção de uma distância sanitária do poder. Relacionamento de respeito mútuo, sim; intimidade, jamais". Ainda em 94, proprietários de jornais de toda a América subscreveram, no México, a Declaração de Chapultepec ${ }^{2}$, onde garantem que "toda pessoa tem o direito de buscar e receber informação, expressar opiniões e divulgá-las livremente. Ninguém pode restringir ou negar estes direitos". Em 1977, em discurso na Associação Brasileira de Imprensa, o diretor-presidente das Organizações Globo, Roberto Marinho, enfatizava: "Proclamamos o dever do jornalista de tornar público todo procedimento que lesa o bem comum, não pelo simples alarde do erro mas para exigir dos responsáveis que façam cessar o erro. E o dever de perseverar mesmo quando sofra o peso do arbítrio ou o vazio da indiferen- ça" 3 . E uma campanha da RBS - Rede Brasil Sul de Comunicação, no Rio Grande do Sul e Santa Catarina, em 1992, com o lema "Comece agora, comece por você" lembrava, em manifesto publicado em 16 de agosto daquele ano, no Diário Catarinense, de Florianópolis, que "Cada um de nós precisa aceitar que a crise ética e moral que enfrentamos hoje começa no atraso para o encontro, na desculpa deslavada, na palavra empenhada e depois esquecida" ${ }^{4}$.

A esse conjunto de declarações podemos chamar de "cinismo ético" que, na abstração da retórica, não encontra correspondência prática radical.

\section{O AUTOR}

Francisco José Castilhos Karam

Professor do Departamento de Comunicação da Universidade Federal de Santa Catarina e Membro da Comissão Nacional de Ética e Liberdade de Imprensa da Federação Nacional de Jornalistas.

1. GARCIA, Alexandre. O servilismo dos sem-caráter. Revista Imprensa, ano VII, n.78. São Paulo, março 1994, p. 40-41.

2. A Declaração de Chapultepec reúne dez princípios que devem nortear a atuação dos jornais vinculados à Sociedade Interamericana de Imprensa (SPI), estabelecidos depois de discussões efetivadas em reunião da entidade, na Cidade do México, em março de 1994.

3. Cf. Folha de S. Paulo, 06.06.77, Jornal dos Jornais, Alberto Dines.Apud: FERNANDES NETO, Antônio. Jornalismo e Liberdade (de Locke a Kennedy). São Paulo: Pannartz, 1980, p.82.

4. Diário Catarinense, Florianópolis, 16 de agosto de 1992, p. 36. 
Lembramos desse cinismo quando a memória nos acena com o jornalista portavoz do último presidente do regime militar, que escreveu um livro lembrando as qualidades do general João Figueiredo e que, na própria Globo, tornou-se uma espécie de porta-voz de todos os governos federais que cobriu, como profissional, à porta do Palácio do Planalto.

O mesmo cinismo se apresenta quando recordamos que muitos empresários de jornais acham que diploma e registro profissionais atentam contra a liberdade de expressão mas impedem fontes de se manifestar, atenuam declarações contra seus interesses particulares e acentuam aquelas que mais os favorecem.

Rememoramos, ainda, esse cinismo quando a prática mostra as dificuldades do jornalista em perseverar "mesmo quando sinta o peso do arbítrio" - que pode se chamar demissão, por exemplo - "ou o vazio da indiferença" - o desemprego, também por exemplo.

Não nos esquecemos desse cinismo, quando os acordos morais tão defendidos pela empresa que se dedicou à campanha de resgate de valores éticos, não têm, eventualmente, correspondência na prática, e há descumprimento de legislação trabalhista ou defesa de interesses escusos. $\mathrm{O}$ acordo coletivo entre Rede Brasil Sul e jornalistas catarinenses não impediu, embora assinado, que um veículo como o Diário Catarinense (da RBS) cortasse declarações, à revelia do sindicato, quando este enviou, para publicação, documento relativo ao Dia Mundial da Liberdade de Imprensa, embora a Coluna dos Jornalistas fosse uma conquista formalizada no acordo assinado pelas duas partes.

\section{MERCADO E ÉTICA}

Ao mesmo tempo, não raras vezes, experientes jornalistas ou bem sucedidos empresários da comunicação falam muito mal da educação brasileira e das escolas de comunicação, incluindo as com habilitação em Jornalismo. É claro que há problemas aí, mas não são exclusivos das escolas e também não são os maiores, do ponto de vista técnico e moral.

Por isso, ao falarmos em ética e técnica, é bom lembrar que a cobertura jornalística tem, ultimamente, em alguns casos, se aproximado do já comentado cinismo, especialmente a desenvolvida por alguns telejornais, particularmente o Jornal Nacional, da Rede Globo de Televisão. O esplendor tecnológico, neste caso, é inversamente proporcional à miséria informativa e à compreensão dos acontecimentos. Talvez por isso tenha havido, recentemente, algumas substituições na direção de jornalismo e nas tendências da informação jornalística da emissora. É uma preocupação que redefine funções e nomes, na tentativa, quem sabe, de preservar a acalentada diferença entre jornalismo e marketing, ou jornalismo e jornalismo chapa branca. É claro, a mudança na direção de jornalismo da Rede Globo, em julho de 1995, melhorou a qualidade jornalística, mas não atende, ainda, os princípios tão defendidos em manuais, encontros ou discursos.

O episódio Ricupero, nas eleições de 1994, serviu, por sua vez, para mostrar, com fulgurante desenvoltura, a confiança que o Poder Público, expresso momentaneamente e, no caso, pelo governo federal, deposita na Rede Globo de Televisão. A conversa do ex-ministro foi emblemática de uma situação que teima em repetir-se, em variados veículos e circunstâncias, envolvendo o jor- 
nalismo brasileiro. De certa forma o público fez, em casa, jornalismo. Mas o fato tornouse jornalístico não porque houvesse investigação, mas porque há tecnologia, há antenas parabólicas, há gente gravando declarações para as quais os profissionais experientes deveriam estar atentos, mas muitos preferem esconder. Não houvesse registro, gravação, parabólicas, as declarações de Ricupero, apesar de cumprirem todos os requisitos para serem consideradas jornalísticas - interesse público, relevância social, atualidade, intensidade, ineditismo - seriam compartilhadas no sigilo, na promiscuidade desinformativa que une, muitas vezes, meios e jornalistas ao poder.

Não é à toa que a pesquisa ImprensaGallup, revelada na edição de agosto de 1994 da revista Imprensa ${ }^{5}$, mostra a desconfiança do público da região metropolitana paulista em relação à informação jornalística. Os dados também mostram que, em São Paulo, em comparação com 1987, aumentou o número de ouvintes, telespectadores e leitores que acham que a mídia privilegia interesses econômicos em detrimento da informação jornalística. Mas também nos Estados Unidos caiu a credibilidade da mídia. A tendência de misturar jornalismo e marketing talvez explique bastante isso ${ }^{6}$. Longe de uma autocrítica, os meios repercutem a Economia e a Política, para ficarmos em dois exemplos sintomáticos, sem crítica ao modo de fazer jornalismo. Inúmeras vezes, transformam-se em fatos jornalísticos aqueles compartilhados pelos porta-vozes ou pelos profissionais que vestiram a capa do poder $\mathrm{e}$ prestígio pessoais e se afastaram da investigação. Profissionais que, por limites pes- soais ou editoriais, estão fazendo jornalismo de gabinete, jornalismo de compadre, jornalismo declaratório. O caso Collor, um contra-exemplo, chegou pelo menos dois anos atrasado, e muitos sabiam da trajetória política e pessoal do ex-presidente, até mesmo revistas, jornais, $\mathrm{TV}$ e rádios.

Não raras vezes, a mídia posa de juíza, mas se nega, ela própria, a ser objeto de discussão.

Para lembrar alguns benefícios, tomemos o exemplo da propaganda eleitoral "gratuita" no rádio e na televisão, como a utilizada nas eleições de 1994 . A rigor, ela foi paga pelo governo (Lei 8.713, de 02.10 .93 ), que retira de investimentos em saúde, educação, habitação, transportes, saneamento e comida para "ressarcir" rádios e TV, mesmo que a radiodifusão seja, pela Constituição, considerada "serviço público".

Aqui, a mídia usufrui também de benefícios em relação ao IPMF, não recolhe ICMS sobre a programação, tem imunidade tributária para IPI e tem garantido o subsídio para o papel de jornal, como lembra o advogado José Paulo Cavalcanti Filho?

\section{ERROS ÉTICOS E TÉCNICOS}

A mídia tem apoiado, com exceções, a privatização também de empresas estatais sérias, competentes e confiáveis. O Banco do Brasil é o que mais investe na agricultura. Recolhe anualmente milhões de dólares ao Tesouro Nacional. Mantém planos internos e externos que auxiliam na resolução de

5. São Paulo não acredita na imprensa. Revista Imprensa, ano VII, n 83. São Paulo, agosto 94, p.12-17.

6. Ver sobre o assunto: NÊUMANNE, José. Entre a trincheira de combate e a caixa registradora. Comunicação \& Educação, n 5, jan./abr., 1996. p. 13-22. (N. E.)

7. CAVALCANTI FILHO, José Paulo. E Lord Jones Morreu - Discurso por Controles Democráticos ao Poder dos Meios de Comunicação. In: fe, 1994, p.27-63. (org.) Informação e Poder. Rio de Janeiro: Record; Recife: Fundação de Cultura Casa do Reci- 
problemas sociais, ao contrário de vários bancos privados, mais preocupados com o lucro imediato. Tem socorrido, sistematicamente, empresas privadas de grande porte com injeção de milhões de dólares, como a Varig. É claro que uma instituição que exerce tal finalidade não pode ser comparada com outros bancos privados, cuja rotatividade, arrocho salarial e instabilidade profissional são visíveis. Sempre que empresas se mal das pernas, pedem socorro ao Estado, que dá a elas o que tira de educação, saúde e outros setores vitais para a população brasileira. Isso não é pauta, é claro, e reforça apenas a idéia de cinismo na condu-

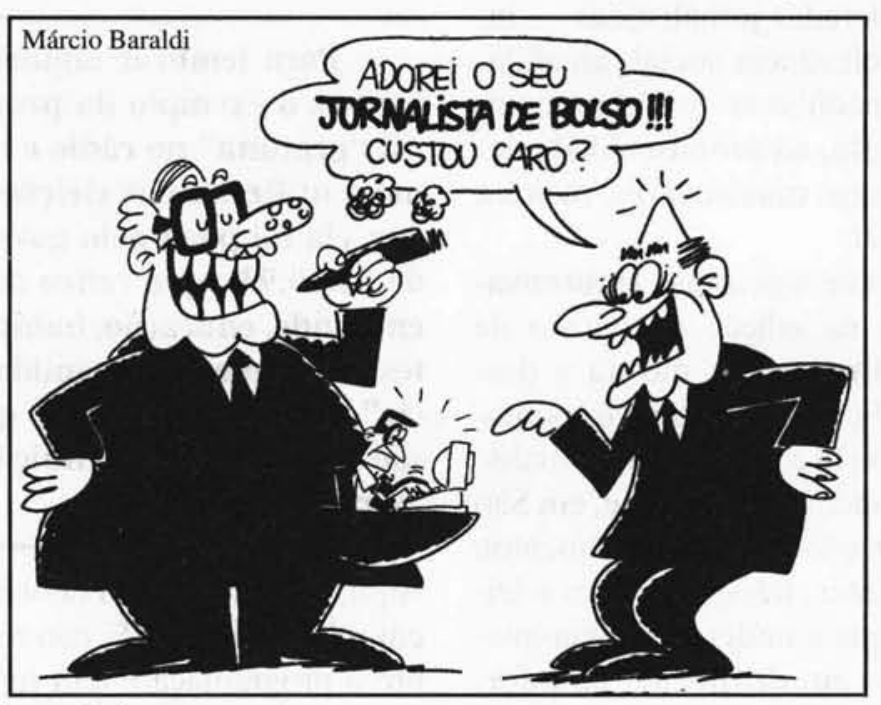
privadas veêm-

Nos Estados Unidos, modelo para os empresários brasileiros de economia diversificada, competitiva e livre, vem aumentando a preocupação com a regulamentação do setor de comunicações, devido às tendências mercadológicas, políticas e econômicas do país e internacionais, para evitar conglomerados de rádios, TV, jornais e revistas que apontem para a concentração desmedida da comunicação e do jornalismo. A preocupação cresce, também, com a promiscuidade que mistura injeções do dinheiro de empresas privadas, como bancos, no capital das empresas de comunicação.

Há preocupação, ainda, com a crescente atuação de empresários de coção de trabalhos jornalísticos.

Há 200 anos, Napoleão Bonaparte declarou que, se perdesse o controle da imprensa, não duraria três meses no poder. Alguns empresários da mídia brasileira parecem querer o poder dos séculos 17 e 18 , só que com as vantagens tecnológicas, financeiras e políticas da véspera do século 21 . Em alguns casos, isso se transforma em medievalismo pós-moderno no fazer jornalístico e nas relações de trabalho e de cidadania.

Mas a mídia raramente se dispõe a ser a pauta de si mesma. Afinal, informação jornalística pode ter muitos nomes. Produção de fatos pode ser o outro nome da isenção ou da verdade. municação em outros ramos de produção de capital, como o sistema financeiro, o mercado imobiliário ou a agropecuária. Lá, a Suprema Corte chegou a estipular que fontes diversificadas e antagônicas são essenciais ao bem público.

O Japão, modelo econômico para muitos empresários da comunicação brasileiros, só não é lembrado quando o tema é estrutura, propriedade, controle e acessos informamesmo tempo, jornais e emissoras de rádio e televisão. Além disso, nenhum concessionário poderá ter mais de uma estação de rádio ou canal de televisão. A mídia brasileira, generosa quando pautas semelhantes são alheias a si própria, é bastante silenciosa quando o tema é meio de comunicação. tivos. Lá, ninguém pode ter ou controlar, ao 
A Operação Rio, que levou o Exército novamente às ruas e que foi um fracasso, é outro bom exemplo. O anúncio da Operação Rio I e II foi cercado por solenidades, pautas generosas e ampla repercussão na mídia dos pontos de vista favoráveis à ação militar. O fracasso da tentativa de intervenção gerou, em esmagadora maioria dos meios de comunicação brasileiros, silêncio quase total, ausência de pautas e sonegação de informações. Problemas sociais não se combatem com baionetas. Elas são ineficazes. No Rio de Janeiro, como em todo o Brasil e na maioria dos países, o Estado tem contra si milhões de pessoas. Elas sabem que, no confronto de interesses, só podem aderir a quem lhes garante escola, saúde, previdência, comida, habitação. Essa garantia atende pelo nome de narcotráfico ou "jogo do bicho". As crianças que nascem, proliferam e se reproduzem nas ruas só podem mesmo aderir ao outro "Estado", que lhes permite continuar vivendo um pouco mais. Contra isso, qualquer violência é inútil, qualquer repressão é inócua.

Mas os efeitos são pauta, a causa não, porque esta é, precisamente, a pedra angular de toda discussão: a estrutura da propriedade privada no Brasil, a essência do capitalismo concentrador, a falta de distribuição de renda e as desigualdades sociais que, para serem resolvidas, precisam ter, no cerne, mudanças na estrutura dos interesses privados minoritários.

Não sendo pauta, os problemas são pouco compreendidos, menos ainda tratados, e as ruas continuarão a produzir medo, mais em quem tem muito do que em quem nada ou pouco tem. O jornalismo de compadre pouco trata disso e, quando trata, vai pouco além do óbvio, e as fontes de opinião são, em geral, repetitivas e viciadas.

\section{PRÁTICA A NÃO SER SEGUIDA}

Mas é interessante lembrar que cinismo ético não se costuma ensinar nas escolas, e ele existe em parte da mídia brasileira. As avaliações otimistas da cobertura jornalística sobre a economia mexicana, feitas há um ou dois anos, não se sustentaram em poucos meses. E não foram estudantes ou recém-formados, mas experientes profissionais que avaliaram mal, por distintas razões, o futuro da economia mexicana.

A falta de conhecimentos globais do mundo não é privativa de estudantes ou jovens jornalistas, mas de experientes e submissos repórteres, editores e analistas. É um problema de cinismo ético, de incompetência técnica, de adesão a interesses particulares no jornalismo, a despeito de todos os discursos, manuais, congressos, declarações e princípios estabelecerem metas a serem atingidas ou obedecidas, como a busca da verdade e da exatidão. Neste caso, a culpa não é da escola, mas dos editores, repórteres e analistas contratados, na grande maioria, hoje, por salários miseráveis e interesses mais miseráveis ainda, por prestígio pessoal ou dividendos particulares de qualquer ordem, em nome de uma informação jornalística irmã do marketing.

Em praticamente todo o mundo, os códigos deontológicos/éticos dos jornalistas e das empresas de comunicação julgam que os assuntos de relevância pública devem ser revelados independente de quaisquer outros interesses. Se isso é reconhecido, se a atividade é tão reconhecida, se os códigos, manuais, declarações de jornalistas e proprietários e princípios como o de Chapultepec afirmam isso; se, ao mesmo tempo, há limites econômicos, políticos, ideológicos para que isso seja realizado, o que precisa ser removido são os limites e não a ética ou a própria profissão, para que ela continue a se 
chamar jornalismo e não qualquer outra coisa, por exemplo marketing.

Isso é possível? Mas se concordamos que o jornalismo deve atender ao interesse público mas trafega em veículos que são, também, comerciais, como exercer as atividades específicas da profissão sem que elas estejam subordinadas, em sua linha editorial, ao projeto político e econômico?

Embora comercial e com nítidos interesses econômicos e políticos, o veículo deve, como essência, preservar a informação jornalística, ancorada em uma teoria sobre a atividade e uma ética específica, tal como a do médico que deve atender, por questões éticas, um paciente moribundo, seja ele de que partido for, seja ele criminoso ou não. É claro que, em outras profissões, há também outros problemas éticos. Mas é forçoso reconhecer que o jornalismo não adquiriu, ainda, do ponto de vista social, o mesmo estatuto moral que a Medicina e o Direito. E a divisão dos profissionais com relação ao cumprimento da regulamentação profissional, ao registro e à formação só acentua isso e deteriora, na base, o próprio reconhecimento da especificidade profissional, com sua teoria, técnica, estética e ética.

É possível dizer que, independente das novas tecnologias e das tendências de mercado, o jornalismo tem um papel relevante $\mathrm{e}$ insubstituível, que continua contemporâneo: contar, sinteticamente ou com mais profundidade, mediante critérios e variações de projetos editoriais, a produção de fatos em campos do saber de difícil compreensão para o cidadão comum, a produção de tendências e interesses em campos particulares ou públicos do poder, a produção de eventos rotineiros mas de interesse público que todos os dias a humanidade produz, com o ritmo, agilidade e periodicidade jornalística, especificamente jornalística, com um profissional dedicado a isso o tempo todo.

Enfim, repetindo, se há limites éticos para o exercício profissional, o que precisa ser removido são os limites e não a ética. Para isso, democracia informativa é fundamental, políticas públicas de comunicação que apontem para isso são urgentes, e um grau mínimo de organizações sociais que participem desse projeto é indispensável, exatamente porque é fundamental um projeto global ético para o jornalismo, para políticas democráticas, públicas e plurais para a comunicação.

Assim, se a mídia reclama da escola porque jovens jornalistas não conseguem, eventualmente, escrever em ordem direta ou apurar com experiência uma informação, por exemplo, deixa de reprovar, como deveria, experientes editores e analistas, autores de graves erros éticos, que resultam em informação repleta de defeitos técnicos.

A escola não suprime fontes antagônicas aos interesses ideológicos das empresas, também não vende matérias como se fossem de interesse público para arrebanhar anúncios ou traficar influência. A escola tem mais o que fazer. Ela também discute a profissão, o que dificilmente as empresas efetiva e profundamente fazem, a não ser para formalizar o que raramente cumprem. É por isso que empresários gostam tanto de declarações como as de Chapultepec, mas na prática não as cumprem, porque preferem o jornalismo de compadre, algo que, definitivamente, a escola não ensina e não deve ensinar. 